and lipid profiles among men. ${ }^{4}$ For Estonia, highly educated adults, compared with those with less education, gained a considerable advantage during the 1990 s, in terms of mortality from circulatory diseases and total mortality. ${ }^{5}$ According to Lawlor and colleagues, the children of these highly educated parents may paradoxically have the poorest insulin resistance profile. We cannot say how much of a paradox this really is, however, as we know nothing about whether their parents as children also had a poor insulin profile.

Genetic, fetal, and early childhood factors should all be relevant in determining insulin resistance. In Lawlor and colleagues' study, parental education was important for insulin resistance among prepubertal and postpubertal children. Parental education can be taken as a measure of social circumstances when their children were born-that is, before the collapse of the Soviet system. Income was measured in 1997-2000; for Estonia this means when new food markets had opened up. In mutual adjustments, education but not income had an independent effect; thus it seems unlikely that it is consumption of "burgers, crisps, and processed food" that is creating the pattern of high insulin resistance among children of highly educated parents. We also noted that, in this study, children of highly educated fathers in Estonia had a $200 \mathrm{~g}$ lower birth weight than others, consistent with their higher insulin resistance.
Anomalies such as those reported for Estonia and Portugal may be of special significance, as they point towards gaps in our understanding and warn against too simplistic a view of health inequalities. Correctly understanding the development of health and mortality in the formerly communist led countries of central and eastern Europe is likely to challenge (and has already challenged) many cherished epidemiological "truths."

We thank Ilona Koupil for important comments to a previous version of this commentary.

Contributors: DV wrote the first version. ML commented and suggested changes. Both authors have read and accepted the final version.

Funding: DV is financed through the Swedish Council for Working Life and Social Research. ML is financed through the Swedish Foundation for Baltic and East European Studies.

Competing interests: None declared.

1 Lawlor DA, Harro M, Wedderkopp N, Andersen LB, Sardinha LB, Riddoch CJ, et al Association of socioeconomic position with insulin resistance among children from Denmark, Estonia, and Portugal: cross resistance among children from Dentr.

2 Marmot MG, Adelstein AM, Robinson N, Rose GA. Changing social class distribution of heart disease. BMj;1978;ii:109-12.

Mackenbach JP, Bakker MJ, Kunst AE, Diderichsen F. Socioeconomic inequalities in health in Europe: an overview. In: Mackenback JP, Bakker MJ, eds. Reducing inequalities in health: a European perspective. London and New York: Routledge, 2002.

4 Vågerö D, Koupil I, Plavinskaya S, Shestov D. Educational differences in mortality 1975-2000 are largely explained by known risk factors among men, but not among women-the St Petersburg cohort study. CHFSS, Stockholm Univerity/Karolinsk Institute, 2005. [Submitted for publica

5 Leinsalu M, Vågerö D, Kunst A. Estonia 1989-2000: enormous increase in mortality differences by education. Int J Epidemiol 2003;32:1081-7.

\title{
Changes in dietary fat and declining coronary heart disease in Poland: population based study
}

Witold A Zatonski, Walter Willett

We previously described a rapid decline in mortality due to coronary heart disease in Poland between 1991 and 1994, corresponding with increases in the ratio of polyunsaturated fat to saturated fat in people's diet and fruit consumption. ${ }^{1}$ The changes in food consumption followed changes in economic policy, including reductions in subsidies for dairy and other animal fats. We describe subsequent trends and use data from cohort studies to estimate the contributions from smoking and diet to these changes.

\section{Methods and results}

Mortality due to coronary heart disease has continued to fall in Poland in both sexes and across educational levels. Compared with 1990, by 2002 for the age band 45-64 years it had fallen by $38 \%$ in men (340 per 100000 to $212 / 100000)$ and by $42 \%$ in women (76/100 000 to 44/100 000). By 1999 (the latest year with comparable data), consumption of saturated fat had fallen by $7 \%$ ( $44.8 \mathrm{~g} /$ day to $41.5 \mathrm{~g}$ /day), consumption of polyunsaturated fat had risen by $57 \%$ (14.8 $\mathrm{g} /$ day to $23.3 \mathrm{~g} /$ day), and the ratio of the two had increased by $70 \%$. Per head, consumption of imported fruit rose from $2.8 \mathrm{~kg}$ /year in 1990 to $8.8 \mathrm{~kg}$ /year in 1991 and $10.4 \mathrm{~kg} /$ year in 1999.

From 1990 to 2004, the prevalence of smoking in Poland fell among people younger than 40 but increased from $23.1 \%$ to $35.2 \%$ among women aged 40-60. Among men, it fell from $51.1 \%$ to $46.1 \%$ at age $40-49$, from $51.1 \%$ to $46.1 \%$ at $50-59$, and from $34.3 \%$ to $28.2 \%$ over 60 . If we assume a relative risk of 3 for current smoking then a reduction in prevalence of $5 \%$ (from 55\% to 50\%) would reduce the risk of coronary heart disease by about $5 \%$. This, and similar declines in rates of coronary heart disease among men and women, indicates that changes in smoking contributed little to falling rates of coronary heart disease.

In the prospective nurses' health study, the ratio of dietary saturated and unsaturated fats was inversely related to the incidence of coronary heart disease. ${ }^{2}$ The change in coronary mortality in Poland was similar to that predicted by the slope relating this ratio to the risk of coronary heart disease in the study (figure). The increased consumption of imported fruit between

Two additional references (w1 and w2) are on bmj.com
Cancer Centre and Institute of Oncology, 5 Roentgena Str, 02-781 Warsaw, Poland

Witold A Zatonsk director of the Cancer Epidemiology and Prevention Division

Harvard School of Public Health, 665 Huntington Avenue, Boston, MA 02115 , USA Walter Willett professor

Correspondence to: W Willett walter.willett@channing. harvard.edu

BMJ 2005;331:187-9 
1990 and 1999 corresponds to a quarter of a serving per day. In the nurses' health study and a companion cohort in men, the relative risk was 0.94 for an increase of one serving of fruit per day, which would predict a reduction of only $1-2 \% .^{3}$

\section{Comment}

The experience of Poland is consistent with epidemiological and clinical evidence ${ }^{4}$ indicating that mortality due to coronary heart disease can be reduced by partly replacing dietary saturated fats with polyunsaturated fats while maintaining a low intake of trans fatty acids.

Polyunsaturated fat reduces serum concentrations of low density cholesterol, ${ }^{4}$ but this cannot account for the size and rapidity of changes in coronary mortality in Poland. A higher intake of polyunsaturated fat also improves endothelial function, reduces platelet aggregability, and reduces ventricular fibrillation. ${ }^{4}$ The net effect can therefore be appreciated only by evaluating coronary end points. Increased intakes of polyunsaturated fat also probably explain most of the major declines in coronary mortality in the United States, United Kingdom, and Australia over several decades. ${ }^{5}$

Both omega 3 fatty acids and omega 6 fatty acids seem to contribute to reductions in coronary risk. ${ }^{4}$
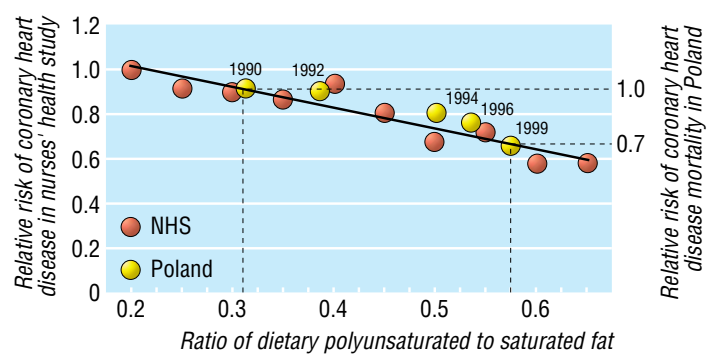

Ratio of dietary polyunsaturated to saturated fat and mortality due to coronary heart disease in Poland (relative to rates in 1990), superimposed on the relation between the fat ratio and coronary risk observed in the nurses' health study. Changes in dietary polyunsaturated to saturated fat in Poland between 1990 and 1999 are predicted to result in a $24 \%$ drop in coronary mortality, which is similar to the observed decline

\section{What is already known on this topic}

Mortality due to coronary heart disease fell drastically in Poland between 1990 and 1994

\section{What this study adds}

This decline has continued through 2002, with most of the decline probably resulting from a large increase in consumption of non-hydrogenated rapeseed and soya bean oil, rather than from reductions in smoking and an increase in fruit intake

According to statistics from the United Nations Food and Agricultural Organisation, ${ }^{\mathrm{w} 1 \mathrm{w} 2}$ the increase in polyunsaturated fat in Poland during the 1990s was primarily from rapeseed and to a lesser degree from soya bean oil; intake of omega 3 and omega 6 fatty acid would therefore have increased, making it difficult to distinguish their relative contributions to the drop in mortality. Statistics from the Food and Agricultural Organisation do not consider changes during processing; but a conscious effort was made in Poland to minimise the trans fat content of margarines made from these oils.

Contributors: Both authors contributed equally to this report and are joint guarantors.

Funding: Part funding from Health Evolution MonitoringClosing the Gap-Reducing Premature Mortality. Baseline for Monitoring Health Evolution Following Enlargement (European Union Grant Agreement No. 2003121).

Competing interests: None declared.

Ethical approval: Not needed.

Zatonski WA, McMichael AJ, Powles JW. Ecological study of reasons for sharp decline in mortality from ischaemic heart disease in Poland since 1991. BMJ 1998;316:1047-51

2 Hu FB, Stampfer MJ, Manson JE, Ascherio A, Colditz GA, Speizer FE, et al. Dietary saturated fats and their food sources in relation to the risk of coronary heart disease in women. Am J Clin Nutr 1999;70:1001-8.

3 Joshipura KJ, Hu FB, Manson JE, Stampfer MJ, Rimm EB, Speizer FE, et al. The effect of fruit and vegetable intake on risk of coronary heart disease. Ann Intern Med 2001;134:1106-14.

$4 \mathrm{Hu} \mathrm{FB}$, Willett WC. Optimal diets for prevention of coronary heart disease. JAMA 2002;288:2569-78.

5 Dwyer T, Hetzel BS. A comparison of trends of coronary heart disease mortality in Australia, USA, and England and Wales with reference to mortality in Australia, USA, and England and Wales with reference to
three major risk factors-hypertension, cigarette smoking and diet. Int J Epidemiol 1980;9:65-71.

\title{
Commentary: Will Europe's agricultural policy damage progress on cardiovascular disease?
}

\author{
Karen Lock, Martin McKee
}

European Centre on Health of

Societies in

Transition, London School of Hygiene and Tropical Medicine, London WC1E 7HT

Karen Lock research fellow Martin McKee professor

Correspondence to: K Lock karen.lock@ lshtm.ac.uk
Trends in cardiovascular disease in Europe have shown an east-west divide for over 30 years. Rapid declines in the European Union contrast with stagnant or rising trends in Russia and central and eastern Europe, with some notable exceptions, such as Poland and the Czech Republic, where rates have fallen since the 1990s. ${ }^{12}$ These improvements are attributed primarily to improved nutrition, ${ }^{12}$ which can be traced to the economic transition that followed political change in the late 1980s.

In Poland many food subsidies, in particular for animal fats, were abolished. Wider availability and lower prices for unsaturated fats and fruits caused rapid dietary changes. Zatonski and Willett explore the impact of these changes, suggesting that the reduction of over a third of coronary heart disease in Poland between 1990 and 2002 can be attributed mainly to increased consumption of polyunsaturated fats, with sustained reduction in saturated fats. ${ }^{1}$ They estimate that the small reduction in smoking and the increase in the intake of imported fruit have made little impact on cardiovascular disease.

The paper clearly shows that dietary change had a major impact on cardiovascular mortality, but the 